\title{
Comparison of position determination accuracy conducted by PPP technique using web-based online service and dedicated scientific software
}

\author{
Grzegorz Krzan, Karol Dawidowcz, Krzysztof Świątek \\ University of Warmia and Mazury in Olsztyn, Faculty of Geodesy and Land Management, \\ Institute of Geodesy, 10-719 Olsztyn, ul. Oczapowskiego 1, Poland
}

\begin{abstract}
Precise Point Positioning is a relatively new technique which can be used to determine high precision 3D position by processing of observations from a single GNSS receiver. For this reason some errors that are mostly eliminated in the differential approach have to be estimated in the PPP. These errors, which are mainly related to physical phenomena, include e.g.: solid earth and ocean tides, carrierphase wind-up, relativistic effects, etc. On the other hand no base stations and no simultaneous observations are necessary to determine receiver position. In recent years, the development of PPP method and GNSS systems allows to effectively deal with the disadvantages of this technique, such as slow convergence times, problematic ambiguity resolution etc.

The aim of this paper is to study the position determination accuracy obtained using PPP technique. Because current commercial software packages do not provide the processing of measurements done using PPP, it is necessary to use scientific software or one of several online services. We processed daily GNSS observations that have been made at two points characterized by different environment conditions. The post-processing of observations covered a variety of development strategies, such as different measurement intervals $(0.5 \mathrm{~h}, 1 \mathrm{~h}, 2 \mathrm{~h}$, $4 \mathrm{~h}$ ) or utilization combined observations from GPS and GLONASS systems.
\end{abstract}

Keywords: GNSS - Global Navigation Satellite System; PPP - Precise Point Positioning; CSRS-PPP - Canadian Spatial Reference System; RTKLIB - software.

\section{Introduction}

Although the mathematical foundation of the precise point positioning method were formulated and widely described in literature relatively long time ago [1], only recently it is gaining increasing interest as a result of more accurate determination of satellite orbits and their clock biases. PPP technique, in contrast with the differential methods, requires only one dual-frequency GNSS receiver. Observations performed by this receiver are post-processed using precise satellite orbits and clock parameters from a various scientific centers like International GNSS Service, Jet Propulsion Laboratory or Center for Orbit Determination in Europe [1-3]. Since observations are performed using a single receiver, in the processing it is necessary to take into account a number of other factors, which influence on the differential approach is reduced by the corrections from Continuously Operating Reference Stations [4]. These factors are: iono- and tropospheric refractions, solid earth and ocean tides, antenna phase-center offsets and variations, carrier-phase wind-up, relativistic effects, etc. [5]. Most of these factors are eliminated in processing through the utilization of products developed by aforementioned research centers or calculated by the used software. Process of calculation of individual corrections has been described so far in many publications [3], [6-8].

One of the key challenges which has to be solved in PPP method is phase ambiguity resolution. The PPP technique often employs a float-type solution which requires long observation time to achieve subdecimeter precision [9]. However, in recent years scientists are developing techniques which may resolve the phase measurement ambiguity. These include for example estimation of the fractional-cycle biases (FCB) derived from ambiguity-fixed GPS network solution [10] or the two-step ambiguity-fixing scheme (wide-lane and narrow-lane) [11]. This approaches effects on reducing the initial convergence period of PPP and improves the solution accuracy [10], [12], [13].

Corresponding author: Grzegorz Krzan. E-mail address: grzegorz.krzan@uwm.edu.pl

http://dx.doi.org/10.3846/enviro.2014.226

(C) 2014 The Authors. Published by VGTU Press. This is an open-access article distributed under the terms of the Creative Commons Attribution License, which permits unrestricted use, distribution, and reproduction in any medium, provided the original author and source are credited. 
Since the PPP technique is used mainly for research purposes, there is no commercial software which can determine the coordinates using this method. It is necessary than to use scientific software such as Bernese, Gipsy-Oasis, Napeos or RTKLIB, or use one of the web-based PPP services. The various methods differ in the processing algorithms and accuracy. In this study we focused on position determination accuracy obtained using CSRS-PPP on-line service which is described in many publications as equal of accuracy to the most precise scientific software [5], [14] and accuracy of position determination obtained with RTKLIB software package which is an open source program package for standard and precise positioning with GNSS. This software is still developed by authors and users. Capabilities for processing static PPP with its use are currently inadequately described in the existing literature.

\section{Methodology of studies}

The observation data used in research were collected in November 2012 and covered six consecutive days. Study concerns the observations performed at 2 sites characterized by different measurement conditions. In order to simulate the optimal measurement conditions, as observations at point A data from ASG-EUPOS reference station KROL in Olsztyn (Poland) were adopted. Whereas the point B was located among urban areas, surrounded by objects hindering the visibility of satellites (Figs 1, 2). Measurement at the KROL were performed with Javad TRE_G3TH Sigma receiver with JAV_GRANT antenna, while at point B with a Topcon HiperPRO receiver with TPSHIPER_PLUS antenna.

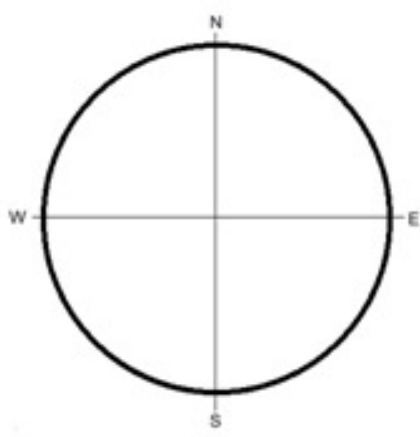

Point A

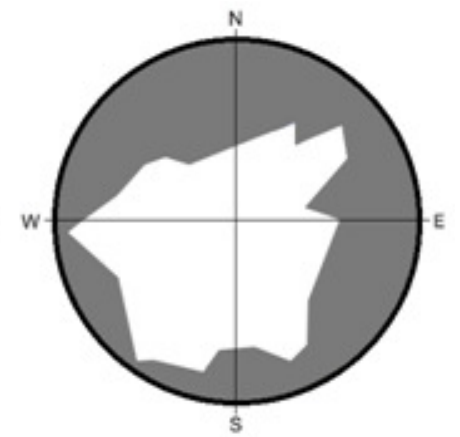

Point B

Fig. 1. Horizon visibility at point A and point B

Six days of 24 hour observations were divided into $4 \mathrm{~h}, 2 \mathrm{~h}, 1 \mathrm{~h}$ and $0.5 \mathrm{~h}$ sessions. Then sessions have been processed using CSRS-PPP service (v. 1.05 03812) and RTKLIB software (v. 2.4.2). Table 1 presents processing options used in both elaborations. Processing characteristics applied in CSRS-PPP are default parameters which user mostly does not have any choice to modify. Options selected for processing by RTKLIB contains a set that gives optimal results in terms of achieved accuracy. NRCan orbit and clock products in initial tests showed the highest precision and allowed the processing of GLONASS signals. The 5-second clock products provided by CODE Institute were also tested but achieved results generally does not differ than 30 s clocks.

Ocean tide loading correction (model: GOT4.7) for RTKLIB were generated by Onsala Space Observatory web site. Differential code bias file applied to RTKLIB processing contained only C1-P1 correction because software does not have capability to input more than one DCB file. Both solutions also differ in terms of ambiguity resolution: CSRS uses a twostep ambiguity-fixing scheme (wide-lane and narrow-lane), while RTKLIB kept in processing float ambiguity. Although the program uses estimation of the fractional-cycle biases (FCB), this option is experimental and becomes unstable. 


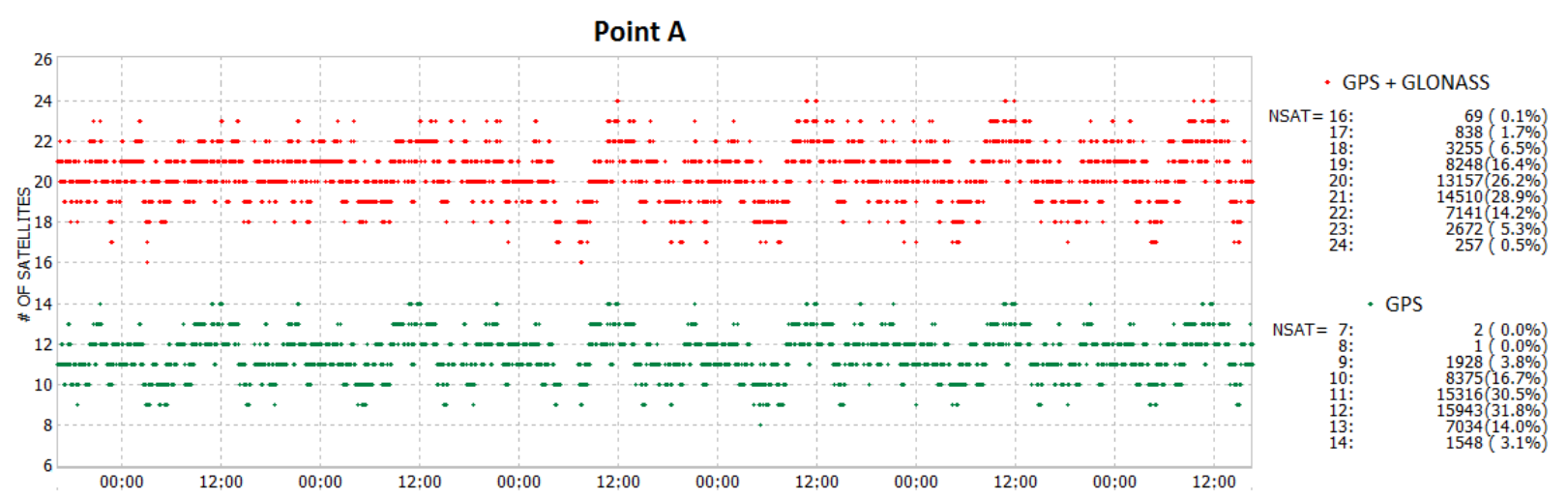

\section{Point B}

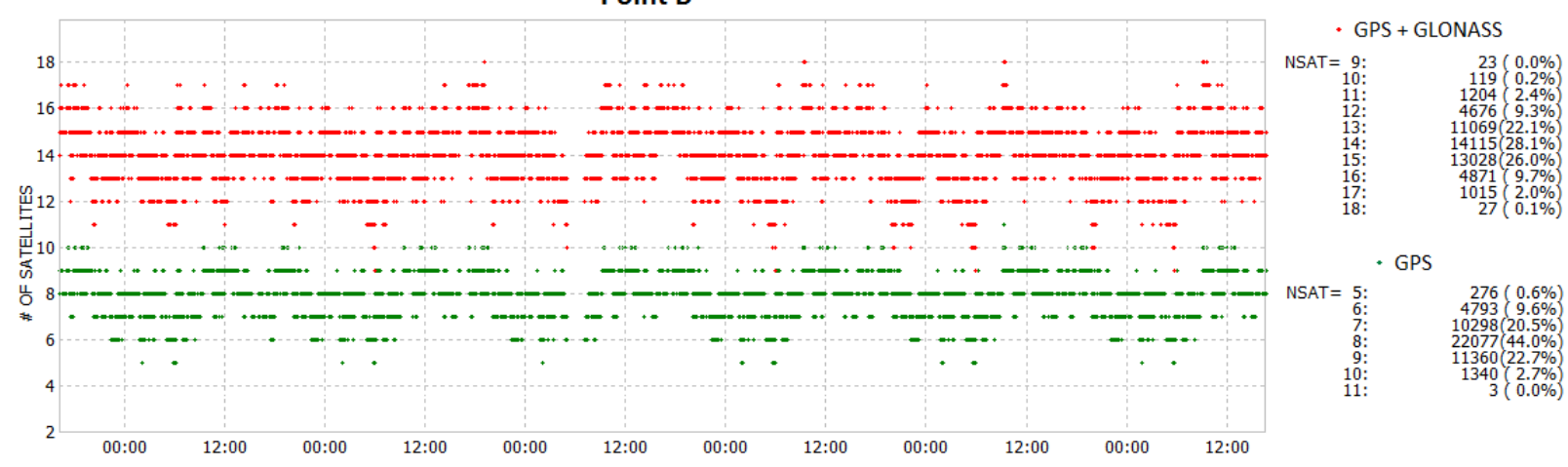

Fig. 2. Satellite visibility at point A and point B during the six days of observations

Table 1. Processing parameters in CSRS-PPP and RTKLIB [15]

\begin{tabular}{lll}
\hline \multicolumn{1}{c}{ Processing method } & \multicolumn{1}{c}{ CSRS-PPP } & RTKLIB \\
\hline Frequency observed & L1+L2 & Code and Phase \\
\hline Observation processed & Code and Phase & ITRF \\
\hline Reference frame & ITRF & NRCan Final \\
\hline Satellite orbits & IGS Final & NRCan 30 s / CODE 5 s \\
\hline Satellite clocks & IGS 30 s Final & Ionosphere-free L1+L2 \\
\hline Ionospheric model & Ionosphere-free L1+L2 & Estimated \\
\hline Marker coordinates & Estimated & Estimated GMF+Gradient \\
\hline Tropospheric delay & Estimated GMF+GPT & Yes (IGS ANTEX) \\
\hline Satellite antenna offsets & Yes (IGS ANTEX) & Yes (IGS ANTEX) \\
\hline Receiver antenna offsets & Yes (IGS ANTEX) & Ellipsoidal \\
\hline Coordinate system & Ellipsoidal & Yes (generated BLQ file) \\
\hline Ocean tide loading & Yes (default NRcan file) & Yes (IGS erp) \\
\hline Earth tides correction & Yes & 10.000 deg \\
\hline Cut-off elevation & 10.000 deg & Yes \\
\hline Phase windup correction & Yes & P1-C1 \\
\hline Differential code bias correction & P1-C1, P2-C2 & GPS / GPS+GLONASS \\
\hline GNSS system & GPS / GPS+GLONASS & No / FCB experimental) \\
\hline Ambiguity resolution & Wide-lane + narrow-lane &
\end{tabular}

\section{Results and analysis}

The following Tables and charts present the results of processing observations by RTKLIB software and compares achieved accuracy with results obtained with web-based PPP service CSRS-PPP. The analysis covered accuracy of northing (N-S), easting (E-W) and height (U-D). Table 2 presents standard deviations of coordinates obtained with post-processing of observations with different time-intervals at points A and B using GPS and GPS+GLONASS systems. Figs 3 and 4 present 
the distribution of differences between estimated positions of measured points and their "true" positions determined as the average coordinates from six days of $24 \mathrm{~h}$ observations.

Table 2. Standard deviations of northing (N-S), easting (E-W) and height (U-D) for all processing variants [m]

\begin{tabular}{|c|c|c|c|c|c|c|c|c|c|c|c|c|c|}
\hline \multirow{3}{*}{\multicolumn{2}{|c|}{$\begin{array}{l}\text { Point / } \\
\text { Interval }\end{array}$}} & \multicolumn{6}{|c|}{ CSRS-PPP } & \multicolumn{6}{|c|}{ RTKLIB } \\
\hline & & \multicolumn{3}{|c|}{ GPS } & \multicolumn{3}{|c|}{ GPS+GLONASS } & \multicolumn{3}{|c|}{ GPS } & \multicolumn{3}{|c|}{ GPS+GLONASS } \\
\hline & & $\mathrm{N}-\mathrm{S}$ & E-W & U-D & $\mathrm{N}-\mathrm{S}$ & E-W & U-D & $\mathrm{N}-\mathrm{S}$ & E-W & U-D & $\mathrm{N}-\mathrm{S}$ & E-W & U-D \\
\hline \multirow{4}{*}{ A } & $4 \mathrm{~h}$ & 0,005 & 0,009 & 0,009 & 0,006 & 0,014 & 0,015 & 0,013 & 0,029 & 0,029 & 0,017 & 0,032 & 0,033 \\
\hline & $2 \mathrm{~h}$ & 0,009 & 0,017 & 0,018 & 0,008 & 0,019 & 0,019 & 0,042 & 0,066 & 0,070 & 0,031 & 0,058 & 0,061 \\
\hline & $1 \mathrm{~h}$ & 0,018 & 0,037 & 0,034 & 0,013 & 0,033 & 0,029 & 0,061 & 0,099 & 0,086 & 0,043 & 0,081 & 0,089 \\
\hline & $0.5 \mathrm{~h}$ & 0,033 & 0,068 & 0,065 & 0,025 & 0,048 & 0,050 & 0,095 & 0,146 & 0,152 & 0,068 & 0,124 & 0,148 \\
\hline \multirow{4}{*}{$\mathrm{B}$} & $4 \mathrm{~h}$ & 0,007 & 0,011 & 0,014 & 0,007 & 0,014 & 0,020 & 0,022 & 0,097 & 0,051 & 0,025 & 0,090 & 0,046 \\
\hline & $2 \mathrm{~h}$ & 0,013 & 0,030 & 0,033 & 0,010 & 0,023 & 0,025 & 0,047 & 0,141 & 0,081 & 0,034 & 0,122 & 0,082 \\
\hline & $1 \mathrm{~h}$ & 0,025 & 0,072 & 0,052 & 0,024 & 0,050 & 0,046 & 0,083 & 0,207 & 0,157 & 0,078 & 0,201 & 0,157 \\
\hline & $0.5 \mathrm{~h}$ & 0,047 & 0,132 & 0,122 & 0,046 & 0,092 & 0,092 & 0,125 & 0,286 & 0,266 & 0,139 & 0,311 & 0,269 \\
\hline
\end{tabular}

Analyzing the results contained in Table 2 it is visible that the standard deviations of coordinates obtained from RTKLIB post-processing are approximately three times higher than those obtained from CSRS-PPP service. It is also shown that accuracy of N-S coordinate is approximately two times higher than E-W and U-D coordinates for all time and signal variants. This situation may be caused by lack of fixing the ambiguities to integer in RTKLIB what results in reducing position quality, especially in easting component [10]. This can be clearly visible in the below charts (Figs 3 and 4).

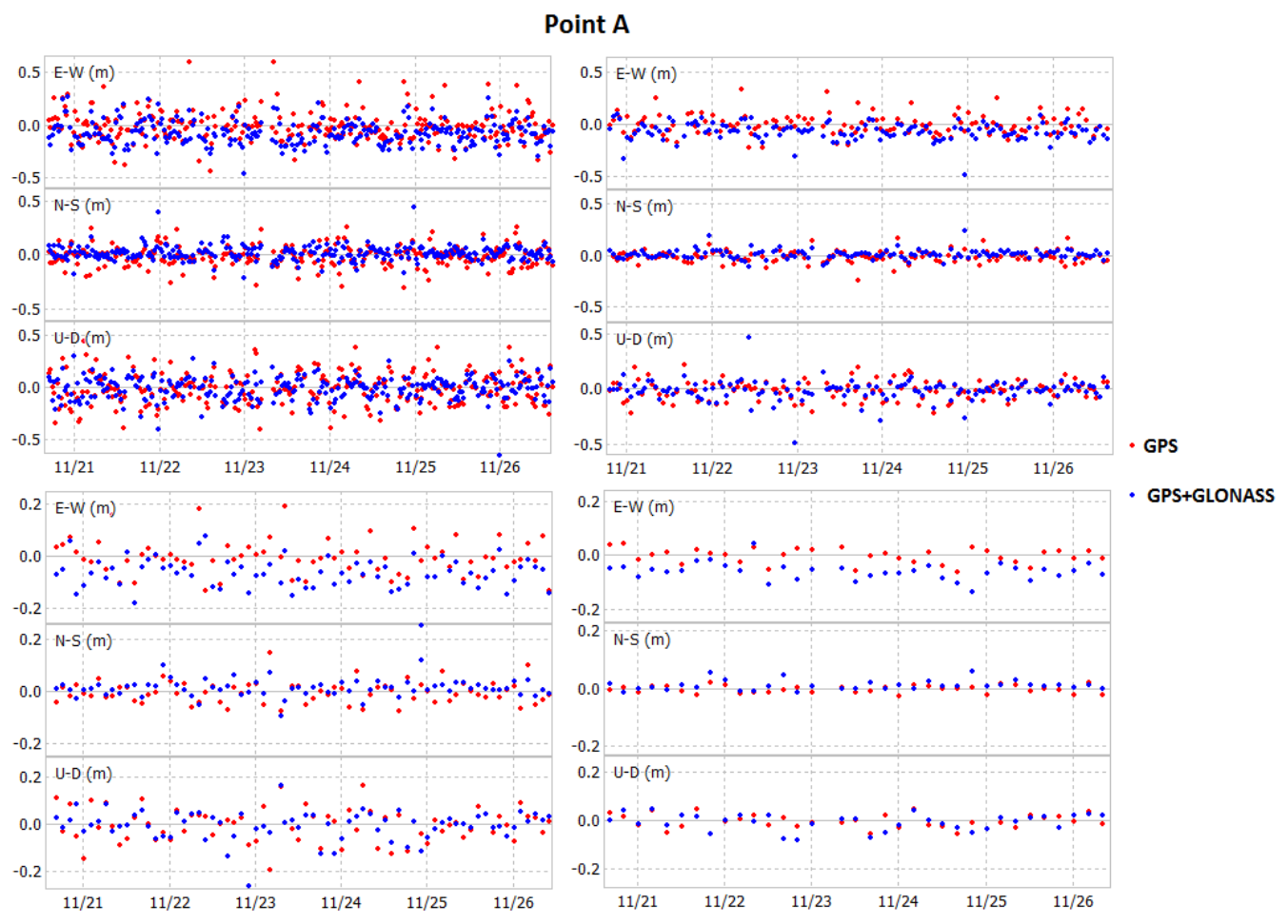

Fig. 3. Easting (E-W), northing (N-S) and height (U-D) differences between estimated and "true" position for point A obtained using RTKLIB software

Keeping float ambiguities also increases influence of multipath and noise to position determination what is visible in comparison of processing results for point A and B. Estimated coordinates of point B characterized by limited horizon visibility achieved significantly less accuracy in all processing variants what can be seen at charts of its position (Fig. 4) which are much more dispersed than charts of point A. As in the elaboration performed with CSRS-PPP, doubled the observation time resulted in lowering standard deviation of coordinates approximately half in all processing variants. 


\section{Point B}
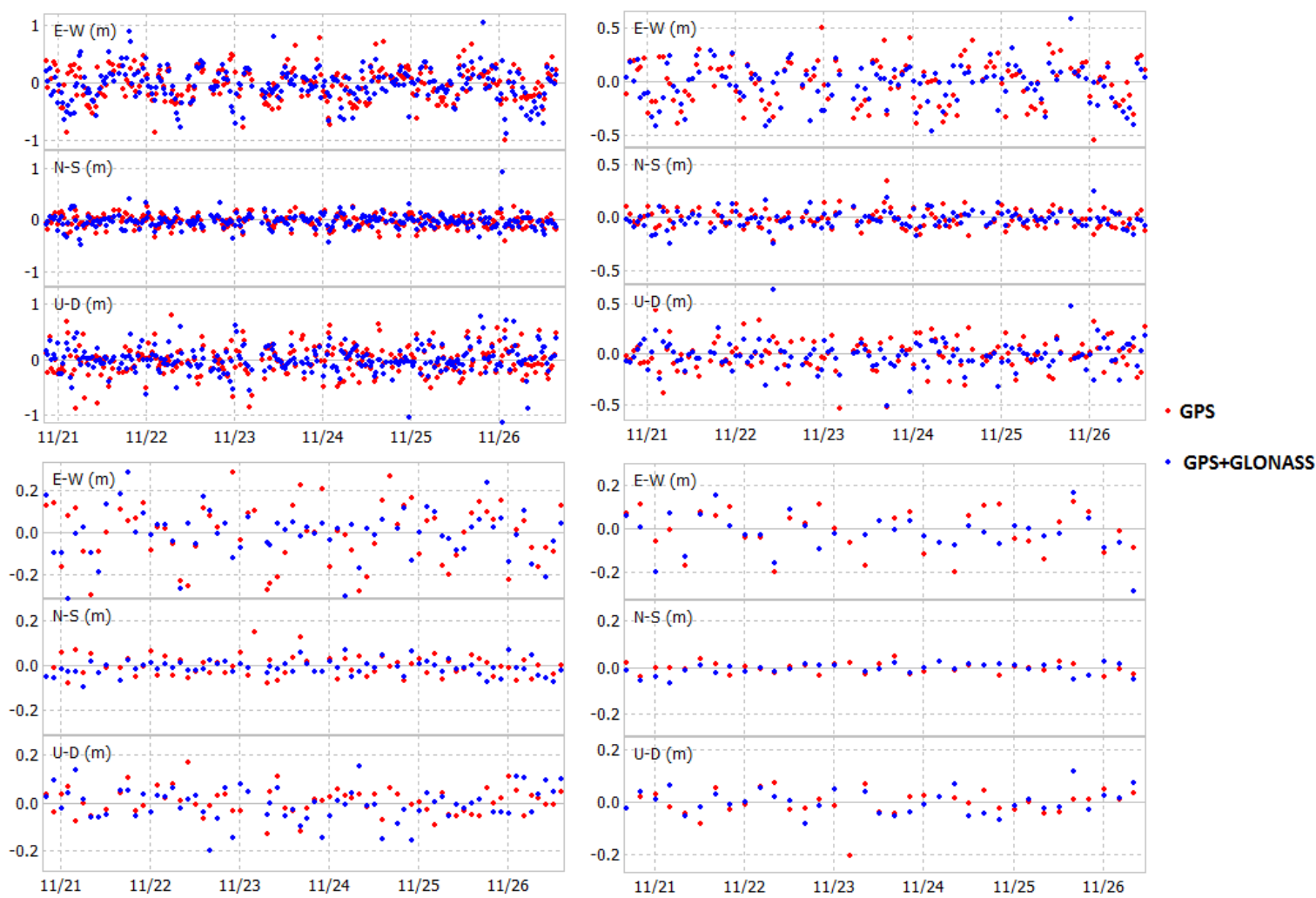

Fig. 4. Easting (E-W), northing (N-S) and height (U-D) differences between estimated and "true" position for point B obtained using RTKLIB software

On Fig. 5 which compares results achieved by CSRS-PPP web-based service and by RTKLIB software are clearly visible all effects of session duration and utilization of GLONASS signals in post-processing. In CSRS-PPP it can be seen that $4 \mathrm{~h}$ observation session results from GPS+GLONASS variant are slightly less accurate than GPS only variant but with the shortening session duration the impact of the use of signals from GLONASS increased the accuracy. This may be caused by the fact that for shorter observation sessions the mayor impact for precision has a number of visible satellites. For sessions longer than 4 hours greater influence would have accuracy of clock and orbit products which are more precise for satellites from GPS system than GLONASS. This relationship is not so obvious for the processing in the RTKLIB software. For point A characterized by optimal observation conditions in most cases situation is similar to those from CSRS-PPP. However there is a difference with respect to point B where utilizing GLONASS signals in processing has not made significant improvement and in some cases even worsened achieved results. If table footnotes should be used, place footnotes to tables below the table body and indicate them with superscript lowercase letters. Be sparing in the use of tables and ensure that the data presented in tables do not duplicate results described elsewhere in the article. 


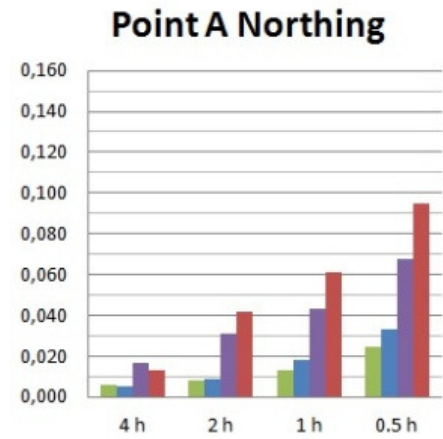

Point B Northing

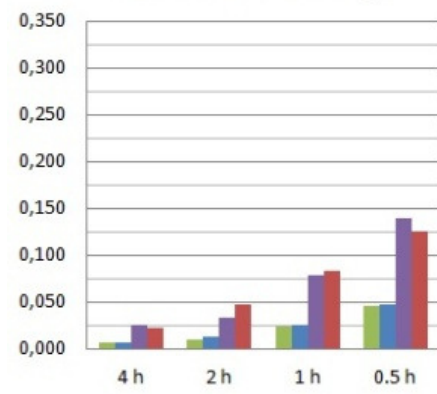

Point A Easting

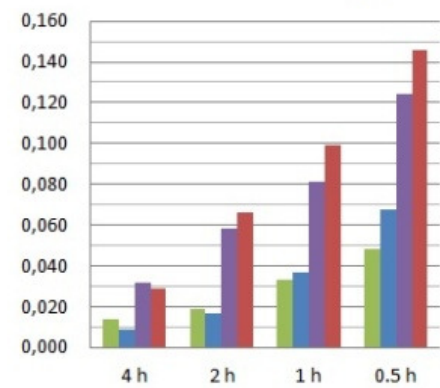

Point B Easting

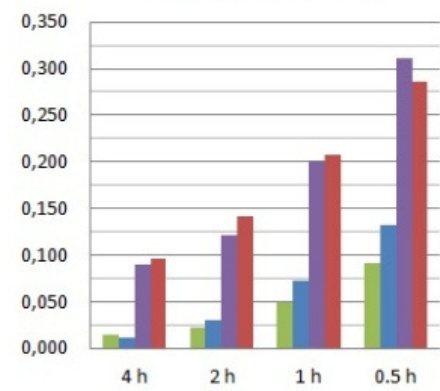

Point A Height

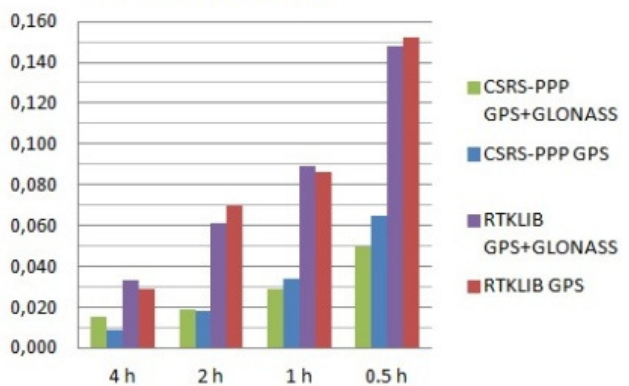

Point B Height

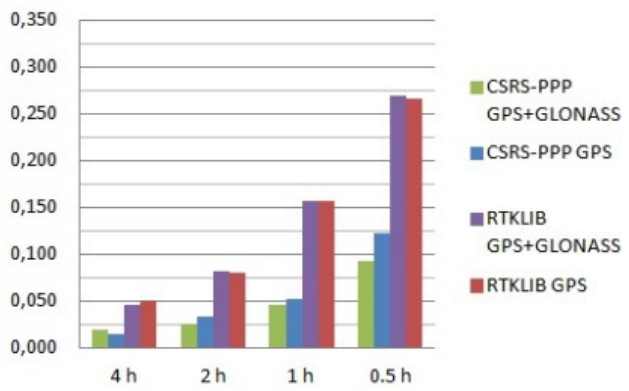

Fig. 5. Comparison of mean 3-D position accuracy obtained by CSRS-PPP online service and RTKLIB software

\section{Summary and conclusions}

In our study, we made a comparison test of the accuracy achieved in post-processing of satellite observations by static-PPP method performed by CSRS-PPP and RTKLIB. These studies were aimed to determine the precision of RTKLIB in the version that is shared by authors to attempt to modify the source code to the needs of further research.

Performed tests showed approximately three times lower accuracy of results achieved by RTKLIB in comparison to those obtained from CSRS-PPP. This situation occurred in all variants of processing due to several factors. The first of these is likely to lack of fixing the ambiguities to integer in RTKLIB as evidenced by significantly lower accuracy of easting coordinate. The program also coped worse with the processing of observations performed at point characterized by limited horizon visibility (B) on which occurred multipath phenomenon. Keeping float ambiguities increases influence of multipath and noise to position determination what can be seen in above charts. Another factor which affects accuracy of position determination may be the lack of possibilities for improvement processing with more than one differential code bias correction. In research the P1-C1 DCB file was used because utilization of it resulted in the greatest increase in the precision of the measurements. It can be assumed that the addition of L1-L2 and P2-C2 DCB correction in RTKLIB post-processing would result in improvement of achieved accuracy. The software is also not fully exploiting the potential of using signal from GLONASS system, especially at point with difficult observation conditions.

Results obtained in research, relating to RTKLIB processing not proved to be satisfactory in comparison to those achieved from CSRS-PPP. However, transparency and form of a program written in an accessible C language as well as regular support makes the program a good foundation for self-development and further research.

\section{References}

[1] Zumberge, J. F.; Heflin, M. B.; Jefferson, D. C.; Watkins, M. M.; Webb, F. H. 1997. Precise Point Processing for the Efficient and Robust Analysis of GPS Data from Large Networks, Journal of Geophysical Research: Solid Earth 102(B3): 5005-5017. http://dx. doi.org/10.1029/96JB03860

[2] Kouba, J.; Héroux, P. 2001. Precise point positioning using IGS orbit and clock products, GPS Solutions 5(2): 12-28. http://dx.doi.org/10.1007/PL00012883

[3] Cai, Ch.; Gao, Y. 2007. Precise point positioning using combined GPS and GLONASS observations, Journal of Global Positioning Systems 6(1): 1322. http://dx.doi.org/10.5081/jgps.6.1.13

[4] Snay, R. A.; Soler, T. 2008. Continuously Operating Reference Station (CORS): History, Applications, and Future Enhancements, Journal of Surveying Engineering 134(4): 95-104. http://dx.doi.org/10.1061/(ASCE)0733-9453(2008)134:4(95)

[5] Mireault, Y.; Tétreault, P.; Lahaye, F.; Héroux, P.; Kouba, J. 2008. Online Precise Point Positioning, GPS World 19(9): 59-64.

[6] Krzan, G.; Dawidowicz, K.; Świątek, K. 2013. Analysis of current position determination accuracy in Natural Resources Canada Precise Point Positioning service, Artificial Satellites 48(3): 111-124. http://dx.doi.org/10.2478/arsa-2013-0010

[7] Van Der Marel, H.; De Bakker, P. 2012. Single versus Dual-Frequency Precise Point Positioning. What are the tradeoffs between using L1-only and L1+12 for PPP?, InsideGNSS 7(4): 30-35.

[8] Stępniak, K.; Wielgosz, P.; Paziewski, J. 2012. Badania dokładności pozycjonowania techniką PPP w zależności od długości sesji obserwacyjnej oraz wykorzystanych systemów pozycjonowania satelitarnego, Biuletyn WAT 61(1): 429-450.

[9] Gao, Y. 2006. Precise Point Positioning and its challenges, Aided-GNSS and Signal Tracking, Inside GNSS 1(8): 16-18. 
[10] Geng, J.; Meng, X.; Dodson, A.; Teferle, F. 2010. Integer ambiguity resolution in precise point positioning: method comparison, Journal of Geodesy 84(9): 569-581. http://dx.doi.org/10.1007/s00190-010-0399-x

[11] Loyer, S.; Perosanz, F.; Mercier, F.; Capdeville, H.; Marty, J. C. 2012. Zero-difference GPS ambiguity resolution at CNES-CLS IGS Analysis Center, Journal of Geodesy 86(11): 991-1003. http://dx.doi.org/10.1007/s00190-012-0559-2

[12] Collins, J. P.; Lahaye, F.; Héroux, P.; Bisnath, S. 2008. Precise Point Positioning with ambiguity resolution using the decoupled clock model, in Proceedings of the Institute of Navigation International Technical Meeting ION GNSS, Savanah, GA, 1315-1322.

[13] Laurichesse, D.; Mercier, F.; Berthias, J. P.; Broca, P.; Cerri, L. 2009. Integer Ambiguity Resolution on Undifferenced GPS Phase Measurements and Its Application to PPP and Satellite Precise Orbit Determination, ION GNSS 56(2): 135-149.

[14] Ebner, R.; Featherstone, W. E. 2008. How well can online GPS PPP post-processing services be used to establish geodetic survey control networks?, Journal of Applied Geodesy 2: 149-157. http://dx.doi.org/10.1515/JAG.2008.017

[15] Takasu, T. 2013. Multiple Constellation PPP with RTKLIB v.2.4.2. GNSS Precise Point Positioning Workshop, Ottawa, Canada, June 14-16 2013. 